\title{
Da produção em massa à customização em massa: sustentando a liderança na fabricação de motores elétricos
}

\section{From mass production to mass customization: sustaining the leadership in the production of electric engines}

\author{
André Gustavo Carvalho Machado ${ }^{1}$ \\ Walter Fernando Araújo de Moraes ${ }^{2}$
}

\begin{abstract}
Resumo
O objetivo deste artigo é analisar como uma empresa líder de mercado lida tanto com a fabricação de motores padronizados quanto customizados, procurando identificar os elementos que corroboram a implementação dessa última abordagem. Nesse sentido, a estratégia de pesquisa foi a de estudo de caso. A análise dos dados foi realizada em cinco fases. Os resultados permitiram constatar que o processo de customização de motores pode se dar em diferentes estágios da cadeia de valor, sobressaindo-se os estágios de fabricação e montagem. Para isso, são desenvolvidas práticas associadas a seis habilitadores: manufatura baseada no tempo, cadeia de suprimentos, flexibilidade do sistema produtivo, projeto do produto, aspectos organizacionais e tecnologia de informação. Conclui-se que, apesar da aparente incompatibilidade entre a produção em massa e a customização em massa, a adoção de ambas as abordagens tem trazido benefícios associados ao intercâmbio de informações, ao conhecimento e à experiência entre as linhas de produtos. Ademais, a análise da demanda por produtos customizados tem subsidiado a decisão para a inclusão dos mesmos às linhas de produtos padronizados.
\end{abstract}

Palavras-chave: customização; padronização; sinergia.

\begin{abstract}
The objective of this paper is to analyze how a market leader works with the production of both standardized and customized motors, trying to identify the elements that corroborate for the development of this last approach. Therefore, the research strategy adopted was a case study. The analysis of the data was accomplished in five phases. The results allowed to verify that the customization process of engines carry out activities in different stages of the value chain, with the predomination of the manufacturing and assembly stages. For this, the following practices associated to six enablers are developed: time-based manufacturing, supply chain, flexibility of the productive system, product project, organizational aspects, and information technology. The conclusion is that, in spite of the apparent incompatibility among the mass production and the mass customization, the adoption of both approaches has been bringing benefits associated to the exchange of information, knowledge and experience among the lines of products. Furthermore, the analysis of the demand for customized products has been subsidizing the decision for the inclusion of the same ones to the lines of standardized products.
\end{abstract}

Keywords: customization; standardization; synergy.

1 Doutor em Administração. Professor Adjunto no Programa de Pós-Graduação em Administração da Universidade Federal da Paraíba (PPGA/UFPB). Endereço:Universidade Federal da Paraíba,Centro de Ciências Sociais Aplicadas, Departamento de Administração - Campus I.Cidade Universitária - João Pessoa-Paraíba - Brasil - CEP:58059-900. E-mail: andremachado@ccsa.ufpb.br

2 Doutor em Administração - University of Manchester - Institute of Science and Technology (UMIST). Professor da Universidade Federal de PernambucoDepartamento de Ciências Administrativas/ Programa de Pós-Graduação em Administração/ (UFPE - DCA/PROPAD)

Endereço: Av. Dezessete de Agosto, 892 - Casa Forte - Recife/Pernambuco - Brasil -CEP: 52060-590. E-mail: wfam@br.inter.net

Artigo submetido em dezembro de 2008 e aprovado em maio 2009 


\section{Introdução}

O propósito deste artigo é analisar como uma empresa líder na produção e na comercialização de motores elétricos na América Latina lida tanto com a fabricação de produtos padronizados quanto customizados, procurando identificar os elementos que corroboram a implementação dessa última abordagem.

A empresa alvo do estudo iniciou suas atividades há mais de 40anos. Atualmente, com 12.000 funcionários, figura entre os cinco maiores fabricantes do mundo e está presente em mais de 100 países nos cinco continentes. $\mathrm{O}$ volume de produção de todas as unidades fabris (a empresa possui 10 parques fabris distribuídos por cinco países) é de, aproximadamente, 50.000 motores/dia, compreendendo motores industriais, motores monofásicos comerciais e motores para eletrodomésticos.

Os motores são fabricados tanto de forma padronizada (onde os clientes não participam de nenhuma etapa do processo de desenvolvimento, fabricação e montagem) quanto de forma customizada (divididos em produtos especiais, que são customizados desde o projeto, e produtos configuráveis, os quais são resultantes da combinação de componentes padronizados). Levando em consideração apenas os motores industriais, aproximadamente, $50 \%$ das vendas são de produtos configuráveis, $30 \%$ são de produtos especiais e apenas $20 \%$, de produtos padronizados.

A diferença entre a produção em massa e a customização em massa é bem documentada na literatura (BERMAN, 2002) e há um grande número de textos científicos que se esforçam, sobremaneira, para compreender a escolha da customização em massa como uma emergente opção estratégica para se obter vantagens competitivas. No entanto, Ahlstrom e Westbrook (1999) e Duray et al (2000) ressaltam que ainda existem lacunas a serem preenchidas quanto a uma orientação adequada sobre as melhores práticas para implementação consistente da estratégia de customização em massa e suas respectivas implicações para o gerenciamento das operações.

Ademais, são escassos os estudos que relatam a experiência de empresas que conseguem obter sinergias mediante a execução, concomitantemente, da produção em massa e da customização em massa em suas operações de manufatura.

Para o desenvolvimento deste artigo, inicialmente, é abordado o contexto competitivo que contribuiu para a mudança do paradigma da produção em massa para a customização em massa. Em seguida, são apresentados os procedimentos metodológicos. Logo depois, discutidos os resultados da pesquisa empreendida, das seguintes perspectivas: razões para adoção da customização em massa, o processo de customização, sinergias e principais habilitadores. Por fim, são delineadas as últimas considerações.

\section{Da produção em massa à customização em massa}

Nos últimos anos da década de 1980, assistiu-se, na percepção de Kotler (1989), à morte dos mercados de massa para bens padronizados e à crescente valorização da segmentação, a qual está evoluindo em direção à customização em massa. O fato é que a fabricação em série de produtos uniformes e com preço baixo pressupõe:

- um contexto econômico estável e pouco complexo, composto por mercados grandes e homogêneos, fundamentado num rígido conceito de fábrica, traduzido na limitada variedade de produtos com longo ciclo de vida;

- detalhada engenharia de processo;

- operações repetitivas utilizando mão-de-obra facilmente treinável;

- estabilidade tecnológica; e

- grande escala produtiva para obter custos baixos (BACIC, 1996). 
Entretanto, intensas transformações emergiram no ambiente competitivo, marcadas principalmente pela instabilidade da demanda, fragmentação dos mercados, redução do ciclo de vida dos produtos, rápido desenvolvimento tecnológico, adoção de modelos de gestão integrada e pelo surgimento de novos métodos de fabricação. Esses fatores, atuando de formas distintas nas diferentes indústrias, expuseram a fragilidade e os limites do sistema de produção em massa (HART, 1995; LAU, 1995).

A perda da estabilidade da demanda, fruto do deslocamento do poder das empresas para os clientes e do acirramento da concorrência, por exemplo, tornou as previsões de vendas e o planejamento de produção mais complexos, encarecendo os custos para amortecer a incerteza inerente aos níveis de produção adequados para atender ao volume de vendas. Essa nova realidade exige a fabricação de uma maior variedade de produtos, lançados no mercado a espaços de tempo cada vez mais curtos, na tentativa de satisfazer os desejos de consumidores cada vez mais volúveis. Aumentar a variedade de produtos fabricados, por seu turno, frequentemente, acarreta alta variedade de partes, de processo e de roteiros de produção. Tal variedade, somada à redução do ciclo de vida dos produtos, tornou mais difícil o percurso da operação na curva de aprendizado, reduzindo os benefícios gerados sobre os custos unitários de produção.

Consequência semelhante foi observada quanto aos benefícios da economia de escala. Com a alta variedade de produtos, inevitavelmente, os lotes de produção diminuíram de volume, ao passo que os custos indiretos aumentaram, decorrentes da necessidade de um melhor gerenciamento, que dê conta da maior complexidade da operação.

Por seu turno, o acelerado desenvolvimento de novas tecnologias, juntamente com a utilização de modelos de gestão integrada e de novos métodos de fabricação, tem propiciado às empresas contornarem certos trade offs. É o caso daqueles relacionados à qualidade ou ao baixo custo, à variedade ou ao volume de produção, à eficiência ou à customização, atingindo, assim, níveis de desempenho superiores e acirrando ainda mais a concorrência nos mercados (ADDIS; HOLBROOK, 2001; DAVIS; AQUILANO; CHASE, 2001; SHEWCHUK; MOODIE, 2000).

Nessa perspectiva, a natureza da competição em muitas indústrias tem se modificado, acarretando sérias implicações para a estratégia empresarial. No novo cenário, os produtores têm entendido que os compradores não podem mais ser agrupados em um imenso mercado homogêneo, mas que são indivíduos cada vez mais exigentes e conscientes da sua importância na cadeia produtiva, ansiando por produtos e serviços diferenciados, que supram as suas necessidades de acordo com suas preferências individuais (PEPPERS; ROGERS, 1997).

Os produtores compreenderam, pois, que não basta fabricar produtos padronizados, em grandes volumes, com qualidade e custos baixos, e sim migrar de uma economia de escala para uma economia de escopo, de forma a permitir a disponibilização de múltiplos produtos a custos mais baixos do que poderiam ser conseguidos individualmente (GOLDHAR; JELINEK, 1983). Além disso, eles perceberam que, reduzindo os ciclos de vida dos produtos e fragmentando a demanda, poderiam obter grande vantagem competitiva, caso tivessem a habilidade de agregar flexibilidade e velocidade ao sistema produtivo, tornando-o capaz de responder às incertezas ambientais e às variabilidades internas rapidamente e com menor custo (PINE, 1994).

Por conseguinte, o padrão mercadológico até então vigente no âmbito da produção em massa, caracterizado por uma grande ênfase no produto e em tentativas de encontrar clientes para o que era produzido, parece entrar em declínio em ambientes caracterizados por grandes turbulências (PINE, 1994). Diante disso, o sistema de manufatura que privilegie o atendimento da demanda sob medida é uma tendência inevitável no mundo industrializado. Isso ocorre não apenas pelo potencial de redução de custos operacionais, mas também pelos benefícios advindos da eficiente utilização das informações coletadas, que possibilita agregar valor significativo às organizações e criar novos produtos e serviços, levando a um processo decisório de maior qualidade.

Contudo, o paradoxo desafiador para as empresas é que os clientes desejam, essencialmente, bens e serviços que atendam às suas necessidades individuais a preços semelhantes aos produzidos em massa. Logo, torna-se cada vez mais necessário fabricar produtos personalizados sem abrir mão dos benefícios de custo proporcionados pelas técnicas de produção em série. Assim, a estratégia de customização em massa vem assumindo uma posição de destaque no posicionamento das empresas de determinados setores produtivos. 
Prover produtos personalizados a custos baixos e no curto prazo, todavia, implica a adoção de uma maneira de agir diferenciada para gerir as atividades que compõem a cadeia de valor, bem como novas formas de realizar negócios entre os elos da cadeia de suprimentos. Tome-se o caso da área de operações.

Enquanto a fabricação e entrega de produtos padronizados permitem alcançar os benefícios da economia de escala, traduzidos principalmente na redução dos custos unitários de produção, à medida que se aumenta o volume produzido e vendido, produtos fabricados sob encomenda têm mais dificuldade para usufruir dessa relação. Se as empresas tradicionais podem estocar os seus produtos acabados para reduzir o tempo de entrega dos pedidos dos clientes, o mesmo não pode acontecer com produtos customizados.

Numa linha de produção tradicional, que trabalha com grandes lotes de produtos padronizados, os funcionários podem se permitir fabricar uma percentagem de produtos defeituosos, pois estes serão diluídos no montante produzido de acordo com as especificações. Numa produção em lotes unitários, no entanto, caso haja falhas internas, poderá haver a exigência de que o produto em processo seja refugado ou retrabalhado, o que representará $100 \%$ do lote, afetando, sobremaneira, os custos associados à qualidade, bem como o desempenho dos seus respectivos indicadores.

Ademais, enquanto nos sistemas de produção em massa a área de planejamento e controle da produção pode otimizar tanto as suas tarefas de elaboração de um plano mestre de produção quanto de identificação e cálculo das necessidades de recursos, programando as aquisições, montagens e a fabricação de produtos - a partir de previsões de demanda entregues pelas áreas de venda e marketing da empresa -, na produção customizada, esse tipo de informação não se encontra disponível. Nesta, exige-se que a organização seja capaz de rapidamente adaptar seus processos produtivos às necessidades individuais de clientes específicos, a custos que não sejam proibitivos.

Por sua vez, enquanto a fabricação de grandes lotes de produtos padronizados permite reduzir os custos associados ao tempo de preparação das máquinas (set-up), a produção customizada implica trabalhar com lotes unitários de produtos. Isso exige da empresa set-ups de curtíssima duração, possibilitando aumentar a velocidade de fabricação de produtos diferentes e, consequentemente, reduzindo o prazo de entrega aos clientes, item crítico de sucesso no modelo de competição em vigor.

Assim, como se pode perceber, vários elementos têm que trabalhar de forma adequada, individualmente e em conjunto, para a customização em massa se transformar em uma estratégia empresarial eficaz. Tais elementos são entendidos neste artigo como habilitadores da customização em massa e serão alvo de investigação na empresa enfocada.

\section{Procedimentos metodológicos}

A estratégia de pesquisa selecionada foi a de estudo de casos (YIN, 2001). A empresa estudada foi escolhida por que, além da produção em massa, também executa ações associadas à customização dos seus produtos e serviços, é líder de motores elétricos na América Latina e figura entre os cinco maiores fabricantes do mundo.

Para obtenção dos dados necessários, os sujeitos-alvo da pesquisa foram os executivos da empresa selecionada, uma vez que, em princípio, os mesmos detêm a mais completa informação acerca do tema objeto da investigação. O número de entrevistados, por sua vez, decorreu da disponibilidade de acesso. Assim, foram entrevistados profissionais que ocupam os seguintes cargos: diretor de engenharia, gerente de engenharia industrial e gerente de engenharia de motores industriais.

Para a coleta de dados primários foram utilizadas várias fontes de evidência, tais como observação, documentos, registros e entrevistas semiestruturadas (estas adotadas como principal técnica de coleta de dados), as quais foram utilizadas no processo de triangulação de dados. Para execução das entrevistas, foi elaborado um roteiro de tópicos relativos ao problema em foco, contendo 25 questões abertas, divididas em dois blocos. No primeiro bloco, as questões buscaram investigar, de forma ampla, a motivação, os critérios para seleção dos componentes a serem customizados, as características do processo e a extensão da customização, bem como o 
relacionamento entre as atividades. As demais questões, pertencentes ao segundo bloco, tiveram o intuito de diagnosticar as práticas, métodos e ferramentas que poderiam habilitar a empresa a executar a customização em massa, bem como as possíveis sinergias entre os sistemas de produção.

Concluídos os procedimentos de planejamento da pesquisa, foram realizados, inicialmente, contatos telefônicos e por e-mail com representantes da empresa alvo da investigação. Em seguida, as questões centrais envolvidas no roteiro de entrevista, juntamente com uma carta de apresentação, foram enviadas aos respondentes da pesquisa.

O envio das questões centrais constantes no roteiro de entrevista, por sua vez, teve dois objetivos. Em primeiro lugar, permitir que a empresa selecionasse os profissionais mais adequados para responder aos questionamentos. O segundo propósito implicou otimizar o tempo de entrevista, pois o entrevistado poderia colher previamente informações, documentos e registros relacionados às questões elaboradas.

Ao final de cada entrevista, foi solicitado que cada entrevistado respondesse a um pequeno questionário com 11 questões que contemplavam informações básicas sobre a empresa e sua atividade como profissional.

A análise dos dados foi realizada em cinco fases, tomando como referência a técnica de procedimento analítico geral (COLLIS; HUSSEY, 2005) e as considerações de Eisenhardt (1989) e Merriam (1998). A primeira fase pode ser compreendida como uma pré-análise na qual, concomitantemente à observação in loco, ao acesso a documentos e registros e à transcrição das gravações das entrevistas, os pesquisadores adicionavam suas impressões e reflexões.

Em seguida, na segunda fase, foram realizados esforços visando identificar a possibilidade de agrupar os dados em categorias. Nesse sentido, emergiram quatro categorias primárias de análise: motivação para a customização em massa, processo de customização, habilitadores da customização em massa e sinergias entre a produção em massa e a customização em massa.

$\mathrm{Na}$ terceira fase, foi elaborado um relatório contendo uma explanação a respeito das categorias obtidas na fase anterior. Cada relatório foi enviado (por e-mail) para os respectivos representantes da empresa pesquisada. Por meio de uma carta, anexada a cada relatório, foi solicitado que se fizesse uma avaliação a respeito da análise dos dados desenvolvida, com o objetivo de verificar a conformidade dos resultados à realidade observada. Pretendeu-se, por meio desse procedimento, contribuir para o alcance da validade interna dos dados.

De posse dos comentários realizados pelos entrevistados, os pesquisadores, na quarta fase, revisaram a análise previamente realizada, de modo a torná-la o mais realista possível. Os resultados, na quinta e última fase, foram analisados à luz da teoria que fundamenta o assunto enfocado.

\section{Apresentação dos resultados}

\section{Por que incluir a customização em massa nos processos produtivos?}

Um dos fatores envolveu a diferenciação do produto no mercado, conforme destaca o gerente de engenharia industrial, quando diz que "uma das estratégias da empresa em nível mundial é buscar a diferenciação para não competir em nível de preço". Essa afirmação é corroborada pelo diretor de engenharia, quando este declara que "os motores são considerados commodities, e na medida em que são agregadas especificidades no produto e se realiza um atendimento personalizado dos clientes, começa-se a diferenciar no mercado".

A diferenciação por meio da personalização, inclusive, serve como barreira à entrada de concorrentes, uma vez que se exige uma série de competências que devem ser adequadamente desenvolvidas para se atender às exigências dos clientes. A esse respeito, comenta o diretor de engenharia:

Como os grandes clientes internacionais já possuem seus fornecedores de produtos padronizados, normalmente, nós iniciamos o relacionamento atendendo à confecção de produtos especiais, os quais os fornecedores originais não possuem capacidade de atender. Dessa forma, alcançamos a fidelidade 
dos nossos clientes e aumentamos o nível da concorrência, pois os rivais terão que também fabricar produtos customizados para competir no mercado.

Na perspectiva do mercado, diversos autores (BROEKHUIZEN; ALSEM, 2002; HART, 1995; KOTHA, 1996; PINE, 1994; PINE; VICTOR; BOYTON, 1993) interpretaram o ambiente competitivo como um fator que impulsionou mudanças rumo à customização em massa.

Outro fator que motivou esforços pela customização foi a crescente demanda por produtos customizados, como será descrito a seguir. A empresa iniciou suas atividades fabricando unicamente produtos padronizados. Na medida em que começou a atender o segmento de OEM (original equipment manufacturer) começou a produzir, ainda de forma incipiente, produtos customizados. Entretanto, nos últimos 10 anos, concomitantemente ao processo de internacionalização de suas fábricas, a empresa começou a atender mais significativamente os pedidos personalizados, a fim de não ficar limitada às vendas dos distribuidores e revendedores de produtos padronizados. Isso aconteceu, principalmente, a partir da intensificação das vendas diretas para grandes fabricantes do segmento OEM.

Historicamente, os produtos com maior número de customização eram os motores para a linha branca (máquina de lavar, geladeira etc.). Todavia, o que se tem observado é que os motores industriais estão sofrendo essa mesma influência, principalmente, em alguns segmentos do mercado - como na área de compressores, ventilação, bombas etc. -, para atender às exigências de OEM das empresas, seja no Brasil ou no exterior, o que, por conseguinte, exige mudanças radicais na forma de administração interna. "Esse tipo de necessidade acontece todos os dias e em grande volume. Mudamos até a estrutura de engenharia para suportar isso", diz o diretor de engenharia.

Constata-se, em consonância com a literatura, que a existência de uma demanda por produtos e serviços customizados (HART, 1995; KOTHA, 1995; LAU, 1995; MacCARTHY; BRABAZON, 2003; PINE, VICTOR, BOYTON, 1993; SILVEIRA; BORENSTEIN; FOGLIATTO, 2001) é um importante motivador de esforços pela customização. Outro aspecto que motivou a empresa a implementar a customização de seus produtos envolveu a busca por menores custos na fabricação de produtos que atendessem às necessidades particulares dos clientes. Quando se trabalha no segmento OEM, as empresas clientes exigem, constantemente, redução de custos, o que pode se traduzir num menor custo do produto disponibilizado pelo fornecedor ou na participação, junto com os especialistas da empresa cliente, do esforço pela redução dos custos do produto final a ser comercializado no mercado. A segunda opção parece ser a mais viável. O gerente de engenharia de motores industriais comenta a esse respeito:

Sempre é mais fácil obter uma redução maior quando eu trabalho em conjunto com o cliente para descobrir uma solução melhor para o produto final. Quando se trabalha com uma empresa que fabrica compressores, por exemplo, tentamos utilizar o ventilador do motor refrigerando o cabeçote do compressor. Isso faz com que o conjunto tenha um custo menor e um maior desempenho. Individualmente, os beneficios de custos e performance seriam menores.

Assim, a customização por meio da interação com o cliente, desde as primeiras fases do projeto, pode reduzir os custos de ambas as partes, além de agregar mais valor ao produto comercializado. Os benefícios evidenciados a partir do adequado emprego de estratégias de customização em massa nas empresas analisadas também foram relatados em outros estudos encontrados na literatura afim (BERMAN, 2002; DORNIER et al, 2000; KOTHA, 1995; KRIZNER, 2001; RUDDY, 2002; ZINN, 1990).

Por outro lado, fabricar grandes volumes de produtos customizados desde o projeto implica uma maior complexidade para as áreas de engenharia e produção, repercutindo em custos operacionais maiores. A esse respeito, comenta o diretor de engenharia:

Fizemos um programa de padronização há 10 anos atrás (1995), pois estávamos entrando em colapso pelo grande número de motores especiais (45\% do total comercializado). Após esse programa, 
tornamos o produto o mais modular possivel e, com isso, passamos a comercializar $80 \%$ dos produtos por meio de customizações decorrentes da modularização de peças e componentes e apenas $20 \%$ provenientes de customizações a partir do projeto. Além disso, criamos um configurador na área de vendas que contribuiu para viabilizar o processo de customização em massa, uma vez que é possível observar, por meio do software, as configurações disponiveis já realizadas e incorporadas ao sistema, auxiliando o vendedor a configurar o produto junto com o cliente.

Ademais, nos últimos anos, percebeu-se um aumento no número de pedidos exigindo que as modificações ocorram desde o projeto, alcançando, no ano de 2004, 35,8\% dos motores comercializados. Devido a essa mudança percebida no mercado, afirma o gerente de engenharia de motores industriais, tem-se que adotar novas ações administrativas e industriais para que se mude um pouco esse perfil, pois o volume é muito grande.

Hoje, temos 40.000 itens ativos diferentes sendo fabricados. Para se ter uma ideia, quando nós estávamos entrando em colapso (em 1995), tínhamos 25.000 itens. [...] A customização em massa tem que ser inteligente; ou seja, ela deve agregar valor ao nosso negócio, ampliar nossa participação no mercado e prover resultados financeiros para os acionistas.

\section{0 processo de customização}

O primeiro passo para a customização envolve a interação com o cliente, a qual pode acontecer de diferentes maneiras. O cliente pode enviar um produto para a empresa e solicitar que seja desenvolvido um motor para aquele produto. De outra forma, especialistas da empresa podem ser convidados para ir ao encontro do cliente para compreender a aplicação dos motores em seus processos e discutir a melhor solução para atender as suas necessidades. A esse respeito, comenta o gerente de engenharia industrial:

[...] Existe uma empresa cliente localizada nos EUA, na qual temos um pessoal acompanhando o desenvolvimento de novas versões de compressores, a fim de definir o motor específico para aquelas versões. Para outro cliente, localizado na Bélgica, além de existir uma pessoa da nossa empresa internamente às instalações da empresa cliente acompanhando os processos, realizamos reuniões mensais com os engenheiros da empresa-cliente para discutir problemas e novos projetos.

Apesar das customizações nascerem das necessidades dos clientes, o gerente de engenharia de motores industriais explica que:

[...] em certos segmentos de aplicação, nós observamos o mercado e desenvolvemos produtos novos sob a perspectiva da inovação. Criamos algo novo para atender a grupos de clientes que possuem necessidades especificas similares.

No caso de produtos especiais, há reuniões entre a equipe técnica de vendas e o cliente para a identificação de necessidades particulares. As informações então obtidas são posteriormente analisadas, para que seja averiguada a viabilidade do atendimento do pedido. Se for viável, as especificações sobre o produto serão repassadas à área de engenharia, onde serão confeccionados modelos e amostras que, quando aprovados, seguirão para a área de produção (aproximadamente, $30 \%$ das amostras fabricadas transformam-se em produto final).

$\mathrm{Na}$ comercialização de produtos configuráveis, o processo também começa na área de vendas, onde serão analisados os requisitos exigidos pelos clientes e verificada a possibilidade do pedido ser atendido, a partir das opções constantes no configurador do produto. Uma vez entendidas as necessidades reais dos clientes, busca-se oferecer alternativas que correspondam ao desempenho esperado, através de um produto similar ao desejado, de estrutura já padronizada, conforme destaca o gerente de engenharia de motores industriais:

Nem sempre o cliente possui o total conhecimento do produto motor. Ele, muitas vezes, exige certas especificidades que não são importantes para o desempenho do seu produto. Assim, a troca de informações com o cliente é importante para tentar descobrir a sua real necessidade e, talvez, expurgar determinadas especialidades que foram solicitadas por desconhecimento do motor pelo cliente. Assim, essa tarefa realizada pela área de vendas é fundamental, pois por causa de uma 
diferença de $1 \mathrm{~mm}$ de comprimento de chaveta, por exemplo, é feito um motor especial sem nenhuma necessidade.

As alternativas incluídas no configurador, por sua vez, já foram previamente desenvolvidas e testadas, e já existem dispositivos, ferramental e processos pré-definidos de fabricação. Dessa forma, não há interferência da área de engenharia para disponibilização desses produtos. O pedido segue, portanto, diretamente para a área produtiva. São milhares de combinações possíveis e, a cada ano, são criadas mais de 30.000 novas opções de estruturas de produtos.

Os estágios da customização serão definidos conforme o grupo de produtos a ser comercializado. Caso seja necessário disponibilizar produtos especiais, a customização ocorre desde o projeto para a fabricação do novo produto, quando a empresa e cliente atuam juntos já na sua concepção.

Por outro lado, se for possível atender os pedidos por meio da combinação dos módulos de componentes padronizados dos produtos, a customização ocorre nos níveis de fabricação e montagem, utilizando-se o configurador de produto como suporte para a operacionalização da tarefa.

Observa-se, portanto, que as atividades associadas à customização dos produtos podem ocorrer a partir de diferentes estágios da cadeia de valor: projeto, fabricação ou montagem. Esses resultados estão em consonância com os resultados das pesquisas empreendidas por Amaro, Hendry e Kingsman (1999), Carmo e Gavronski (2002) e MacCarthy, Brabazon e Bramham (2003), os quais destacaram haver mais de um nível de customização proporcionado por uma empresa a seus clientes.

\section{Sinergias para fabricar tanto produtos padronizados quanto customizados}

Na medida em que é fabricado um produto especial ou configurável, caso haja demanda, as características desenvolvidas podem ser incorporadas às linhas padronizadas, conforme destaca o gerente de engenharia de motores industriais:

Quando observamos que há uma potencialidade de demanda no mercado, procuramos incorporar as especificidades de alguns dos produtos especiais nas linhas de produtos modulares. É o que aconteceu, por exemplo, com motores que foram fabricados para certos ambientes agressivos à vida útil dos produtos, tal como fábricas de papel ou siderúrgicas. Muito do que observamos e especificamos para aqueles ambientes foram, ao longo dos anos, sendo incorporados às linhas normais.

Muitos aspectos técnicos que há 10 anos eram considerados especiais, devido à evolução tecnológica e às crescentes exigências do mercado, tornaram-se especialidades opcionais e, logo depois, um padrão. Por outro lado, ao invés de uma postura reativa, pode-se dirigir o mercado para isso, agregando mais valor aos produtos. O sistema de isolamento do motor, antigamente, era classe "B". Hoje, de forma padronizada, já utilizamos classe " $F$ ", afirma o gerente de engenharia industrial.

Ademais, o fato de ter se desenvolvido o know-how, ao longo do tempo, para fabricar produtos padronizados, possibilitou transferir esse conhecimento para a fabricação de produtos especiais e configuráveis. Todo o avanço tecnológico obtido em uma parceria ou no processo de atendimento ao cliente, por sua vez, também pode ser incorporado ao motor padronizado.

\section{Habilitadores da customização em massa}

Por meio da análise dos resultados, pôde-se constatar a utilização de um conjunto de práticas associadas aos seis habilitadores: manufatura baseada no tempo (time-based manufacturing), cadeia de suprimentos, flexibilidade do sistema produtivo, projeto do produto, aspectos organizacionais e tecnologia de informação. Ressalta-se, todavia, que a alocação de certas práticas em determinados habilitadores teve, essencialmente, objetivo didático, uma vez que, como será possível observar, certas atividades podem fazer parte de mais de um habilitador, ainda que sejam tratadas em apenas um deles. 


\section{Projeto do produto}

Tenta-se projetar um produto que utilize o máximo de componentes padronizados, mas também intercambiáveis entre uma grande variedade de opções. O objetivo, portanto, é projetar, desenvolver e produzir componentes que possam ser combinados das mais variadas maneiras possíveis, dando origem a diferentes modelos e variações de produtos finais.

Para reduzir a complexidade e os custos associados à fabricação de produtos especiais, por exemplo, em todos os momentos, a empresa procura utilizar os componentes e estruturas de produtos já configurados. Como salienta o gerente de engenharia de motores industriais:

Como a customização envolvida na fabricação de produtos especiais atingiu um volume mensal de 1.200 produtos, procuramos desencorajar essa demanda, fabricando um produto o mais modular possivel, de forma que a customização não seja algo que venha a mudar completamente o fluxo produtivo. [...] Ainda que haja casos em que não seja possível a adoção de combinação de componentes já configurados, isso não acontece com tanta frequência, pois talvez sejamos umas das empresas que trabalha com o maior número de diversificação do mundo na área de motores. Assim, dificilmente o produto não se encaixa em alguma configuração que nós já fizemos.

Da perspectiva da linha de produtos que podem ser configurados (existem centenas de milhares de produtos que podem ser customizados a partir do configurador), procurou-se identificar quais as especificidades mais solicitadas pelo mercado. A partir daí, foram empreendidos esforços para modularizar os componentes a serem customizados nas diversas linhas de produtos disponibilizados. Mensalmente, são criados cerca de 1.400 produtos, e a base atual possui aproximadamente 100.000 já estruturados. A adoção de módulos para os propósitos da customização em massa está em conformidade com as proposições de Dornier et al (2000), Feitzinger e Lee (1997) e Pine (1994). Além disso, busca-se adequar a estrutura do projeto às características operacionais da área produtiva, de modo a tornar o produto mais facilmente fabricável. Nesse caso, deve haver uma forte interação com as áreas de engenharia industrial e de processos, avaliando quais máquinas e equipamentos serão usados, quais alternativas de modelagem (injeção e fundição) e tecnologia serão adotadas e os custos com os quais se irá arcar, em função do volume a ser produzido, explica o gerente de engenharia de motores industriais.

\section{Manufatura baseada no tempo}

Apesar da adoção da manufatura celular ser apregoada por certos estudiosos (DAVIS; AQUILAN; CHASE, 2001; GAITHER; FRAZIER, 2001; TUBINO, 1999) para reduzir o tempo de manufatura, observou-se que em alguns segmentos a empresa abdicou de utilizar o layout celular em prol do layout por processo. $\mathrm{O}$ gerente de engenharia industrial destaca ter constatado

que quando se trabalha com alta diversificação de produtos, a utilização de células de produção implica em uma menor utilização dos recursos, porque apesar da divisão das células por famílias de produtos, há uma grande necessidade de paradas para set-ups.

Por outro lado, quando se adota o layout por processo, é possível realizar certos set-ups sem interrupções no processo, / Por outro lado, o layout por processo possibilita certos set-ups ininterruptos, sem intervalos, pois enquanto se está realizando uma atividade, pode existir outro equipamento em preparação. Na fabricação de eixos, por exemplo, há um grande volume e uma grande variação de componentes que exigem formas de torneamento diferenciadas. Para se trabalhar com células, por sua vez, seria necessário que o processo de torneamento, para cada célula, fosse semelhante, de modo que atendesse a uma família específica de produtos.

Além disso, quanto ao exemplo anterior, quando se adota o layout por processo, é possível atender a um número maior de famílias de itens para o torneamento porque diminui o tempo de set-up das máquinas, uma vez que existem diferentes tornos para atender a diferentes especificidades, pois os mesmos estão localizados em um setor específico. Com isso, aumenta o nível de utilização das máquinas e a capacidade de produção do 
sistema. Caso fossem adotadas células nesse processo, as mesmas se tornariam gargalos, devido à incapacidade de atender a volumes e variedades tão elevados.

Assim, onde os volumes são menores e os equipamentos são mais lentos, o uso de células de manufatura torna o processo mais eficiente. Entretanto, quando a quantidade e a variedade dos componentes são muitas elevadas, torna-se mais difícil justificar o uso de células.

Outro elemento fundamental para a customização em massa é a forma como está disposto o sistema de produção. O parque industrial está dividido em quatro centrais: central de processamento do núcleo do produto, central para a injeção do induzido, central de usinagem do eixo responsável pela transmissão de potência e central de usinagem de fundidos. Concluídas essas etapas da fabricação, o produção segue para as unidades fabris, de acordo com as famílias de produtos. Nas unidades fabris, são realizadas a montagem e bobinagem, a partir de componentes entregues pelas centrais. Como as etapas de fabricação são separadas, o principal esforço está em coincidir a chegada de todos os componentes no processo de montagem e bobinagem.

Uma vez entendido o raciocínio do diretor de engenharia, pode-se concluir que, considerando o objetivo da customização, a divisão das atividades envolvidas no processamento produtivo apresenta melhores resultados do que a fabricação e montagem de todo o produto em apenas uma unidade ou central produtiva sob o conceito de minifábricas. Os principais benefícios estão associados à otimização dos recursos, pois caso se trabalhasse em minifábricas, ter-se-ia ociosidade de equipamentos, haja vista que na medida em que há a exigência de muita preparação para se atender a produtos diferenciados, o impacto na linha de montagem, em termos de número de paradas, seria muito grande.

Ademais, comenta o gerente de engenharia industrial, a divisão das atividades permite centralizar o conhecimento tecnológico de cada processo numa mesma área, permitindo que seus integrantes percebam mais facilmente tendências e meios de como melhorar os resultados diante da diversidade de produtos, através do desenvolvimento de equipamentos que sejam capazes de atender todas as demandas de variação, por exemplo. Em sua percepção, "seria muito mais complexo alcançar esses resultados, se trabalhássemos com minifábricas ou células de produção". Pratica-se, então, uma gestão participativa, por meio de comitês, comissões e círculos de controle de qualidade (CCQs). Isso é muito importante numa empresa que tenha como objetivo ganhar tempo, pois contribui sobremaneira para despertar em todos na organização o comprometimento com uma meta comum. / pois estimula sobremaneira em todos na organização o comprometimento com uma meta comum.

Da perspectiva do gerenciamento do inventário, são mantidos estoques de componentes acabados nos diversos centros produtivos, para alimentar rapidamente as unidades de bobinagem e montagem, reduzindo, por conseguinte, o tempo de entrega do produto final. Assim, o estoque de motores é de sete dias e o giro de estoque de matérias-primas e produtos em processo é de 17 dias.

Também é utilizada a estratégia de manter estoques nos fornecedores, para que estes forneçam matérias-primas diretamente para as linhas de montagem. O mesmo acontece com os clientes. Para a Multibras, por exemplo, fornece-se diretamente para suas linhas de montagem de geladeiras. Como decorrência das atividades executadas pela empresa, desde a entrada do pedido até a saída do produto, demora-se 12 dias para produtos especiais e seis dias para produtos configuráveis. O lead time de fabricação, no segundo caso, é de quatro dias.

\section{Tecnologia de informação}

A existência de bancos de dados com bibliotecas virtuais de componentes já projetados de produtos permite armazenar e agilizar a busca por características que mais se aproximem das variáveis do pedido solicitado pelo cliente, o que contribui para uma fabricação mais rápida e menos complexa. Nesse sentido, uma alternativa para otimizar as atividades de customização envolve a adoção do software configurador de produto.

Todavia, não é só a geração do modelo e da estrutura do produto que é importante. As formas de gerenciamento e controle dos componentes são igualmente fundamentais, explica o gerente de engenharia de motores industriais. Quando se trata de motores especiais, do ponto de vista da engenharia, como se tem mais de 160.000 itens, é necessário que haja ferramentas de gerenciamento que permitam localizar itens similares aos 
que o cliente deseja e que já se encontram projetados, no menor espaço de tempo possível. É preciso que existam sistemas de informações que agilizem o fluxo de informações entre o cliente, a área de vendas e a engenharia.

Assim, como afirma o gerente de engenharia de motores industriais, são empreendidos grandes esforços para o desenvolvimento de ferramentas de gerenciamento e geração do produto que integrem desde a área de vendas até a ferramentaria, visando ganhar tempo e tornar o sistema produtivo mais flexível para atender às necessidades dos clientes. Apenas na área de engenharia, por exemplo, há quatro pessoas trabalhando exclusivamente para alcançar esses objetivos, dispondo da assistência do Departamento de Sistemas de Informações (DSI).

Para se ter uma ideia do nível de utilização de sistemas de informação, a seguir, é discriminado o fluxo de informações, desde o momento do pedido pela área de vendas até o produto entrar em produção.

O pessoal de vendas alimenta um sistema CRM (Saso - Sales Softwares), o qual dá apoio na configuração dos dados do produto e informa se há necessidade de desenhos e a criação de itens especiais. Esse sistema se comunica com o software de gestão integrada BAAN (sistema ERP), o qual gera o pedido do produto, a ordem de produção ou aponta a necessidade de estruturação de itens novos. O BAAN, por sua vez, comunica-se com o sistema de gerenciamento de dados do produto PDM (product data management), que realiza uma pesquisa para identificar se o componente mecânico já existe. Caso não exista, são criados novos itens e novos desenhos (adotando também sistemas CAD) e realizado o detalhamento elétrico. Por fim, as estruturas completas do novo produto e as notas de operação são transferidas para o BAAN. A importância da adoção de sistemas de informação é corroborada por vários estudiosos sobre o tema da customização em massa (destacando-se: BYRD, 2001; LAU, 1995; ROSS, 1996; SILVEIRA; BORENSTEIN; FOGLIATTO, 2001).

\section{Flexibilidade do sistema produtivo}

A exemplo do que observaram Ahlstrom e Westbrook (1999), Lee e Chen (2000), Pine (1994), Zipkin (2001) e Jiao, Ma e Tseng (2003), o resultado da análise dos dados permitiu constatar que a flexibilidade do sistema produtivo é fundamental no contexto da customização em massa. Nesse sentido, os principais tipos de flexibilidade são: de máquina, volume, mix, modificação de produto e roteiro (em algumas áreas, foram criados sete roteiros alternativos).

A partir da exposição do diretor de engenharia, depreende-se que uma das principais preocupações é agregar flexibilidade às máquinas, investindo em equipamentos programáveis. Ademais, como são disponibilizadas uma grande variedade de características operacionais para os motores, há máquinas de bobinagem, por exemplo, dotadas de dispositivos que permitem a realização do set-up sem interferência humana.

Por outro lado, são empreendidos esforços para realizar trocas rápidas de ferramentas para atender a diferentes mix de produtos, conforme explica o diretor de engenharia:

Para um certo produto, em um centro de usinagem convencional, consome-se aproximadamente 30 minutos para realizar as fixações exigidas para a realização da tarefa. Com o sistema de troca rápida que desenvolvemos, realizamos a tarefa em apenas cinco minutos. Quando não há possibilidade de realizar trocas rápidas nas linhas, nós realizamos preparações de componentes em células separadas, para não afetar a flexibilidade. Isso acontece em dois casos: produtos especiais e quando fabricamos componentes para serem enviados às nossas fábricas no exterior.

Além disso, as linhas de fabricação são balanceadas para atenderem determinadas famílias de produtos; ou seja, elas são dedicadas a isso. Dessa forma, só será preciso realizar modificações se houver necessidade de produtos especiais.

Nesse sentido, o cuidado com a programação do mix de produção é constante, pois dependendo do como sejam realizadas as atividades, produzir 3.000 motores/dia pode demandar mais tempo do que para fabricar 5.000 motores/dia. Por isso, balancear carga com capacidade é fundamental, pois há certos limitadores (como complexidade de fabricação, por exemplo) que devem ser respeitados, caso contrário haverá atrasos na entrega 
dos produtos acabados. Assim, “[...] o que é possível, nós padronizamos, e o restante é confeccionado fora do sistema, para diminuir interferências," comenta o gerente de engenharia de motores industriais.

A seleção das máquinas e equipamentos, por sua vez, é realizada de forma planejada. Essa atividade faz parte de um plano estratégico que define a capacitação para os próximos quatro anos; ou seja, já há uma definição das máquinas e equipamentos que devem ser adquiridos nesse período. Devido às mudanças tecnológicas e ambientais, o plano é revisado anualmente.

A identificação de processos críticos para sua posterior automatização também é um dos objetivos visados, para se alcançar a flexibilidade. Por sua vez, conforme comentário do gerente de engenharia de motores industriais,

[...] estamos constantemente desenvolvendo os sistemas de vendas, para que sejam contempladas ferramentas de engenharia que possam auxiliar na configuração do produto para o cliente. O objetivo é propiciar que o vendedor se aproxime o máximo possivel do cliente, por meio de soluções já concebidas.

Outro aspecto que contribui para aumentar a flexibilidade do sistema produtivo corresponde ao fato de a empresa ser verticalizada, com negócios relacionados à fabricação do fio, fundição e ferramentaria. Em relação à ferramentaria, por exemplo, é por meio dela que se torna possível fabricar não apenas ferramentas, mas também máquinas, internamente. Estas são forças que permitem flexibilidade de modificação de produtos e rápidas adaptações do que o cliente pede, trazendo vantagens em relação aos concorrentes, afirma o gerente de engenharia industrial. Esse achado vai de encontro ao que sugeriram Alford; Sackett e Nelder (2000) quanto à utilização de subcontratados e fornecedores no lugar da produção vertical integrada, como resposta às restrições muitas vezes observadas na cadeia de suprimentos.

\section{Cadeia de suprimentos}

Os fornecedores são envolvidos desde o início do projeto, seja por meio de reuniões ou da troca de informações por meio eletrônico, quando são discutidas aplicações e utilização de ferramentas para atender a novas necessidades.

Um dos critérios relevantes para o sucesso do fornecimento consiste na proximidade física entre a fábrica do fornecedor e a empresa. "Evitamos ao máximo a importação de componentes", afirma o gerente de engenharia de motores industriais. O mesmo continua sua explicação:

Queremos criar o Vale do Motor Elétrico, semelhante ao Vale do Silício nos EUA. Para isso, criamos um centro de excelência em motores com convênio com universidades, trabalhando com especialistas, mestres e doutores na área. Esse trabalho envolve parceiros em um raio de $200 \mathrm{~km}$. Ao redor da empresa, queremos formar pequenos fornecedores com capacidade e excelência internacional para fornecer componentes que fazem parte do produto da empresa, principalmente, componentes importados. Isso já acontece hoje. Auxiliamos dezenas de fornecedores de componentes específicos (que anteriormente pagávamos uma fortuna para importar) a se capacitarem, formamos, ajudamos a certificar seus produtos, e hoje estamos comprando esses produtos e economizando muito dinheiro. $O$ projeto dos componentes a serem fabricados pelos fornecedores, inclusive, muitas vezes nasce aqui dentro mesmo, e depois nós entregamos para eles. Alguns fornecedores são ex-funcionários nossos.

A localização da fábrica do fornecedor junto ao cliente, por sua vez, foi tida por Kotha (1996) como uma das condições para o sucesso da estratégia de customização em massa.

\section{Aspectos organizacionais}

Há uma filosofia participativa, de "portas abertas". A empresa possui um sistema de participação nos resultados que, no ano de 2005, distribuiu 3,6 salários para cada colaborador. Ademais, busca-se, constantemente, a inovação, atualização tecnológica do parque fabril e qualificação das pessoas. Investe-se, pois, tanto em treinamento operacional quanto em pesquisa e desenvolvimento. 
Em termos culturais, a empresa estimula a simplicidade e a redução de custos associados na fabricação de produtos, como destaca o diretor de engenharia:

Nosso papel é preservar a cultura dos fundadores da empresa na busca da forma mais simples, econômica e adequada de fazer motores. Os comitês são a forma de manutenção dessa cultura. As discussões envolvidas são alicerçadas não só nos aspectos técnicos e econômicos, mas também nos aspectos culturais, porque o excesso de sofisticação pode gerar complexidades desnecessárias.

Além dos operadores, a empresa possui mais três níveis hierárquicos - chefe, gerente e diretor -, o que facilita a tomada de decisões. Por outro lado, as decisões originadas nos comitês, ainda que possam ser mais demoradas por envolverem pessoas de diferentes áreas, promovem um nível de coesão maior, gerando maior comprometimento.

As metas, por sua vez, são divididas em quatro níveis: metas gerais da empresa, da unidade, metas departamentais e individuais. A transparência do planejamento estratégico da empresa, permitindo que todos saibam exatamente quais os objetivos nos próximos cinco anos, contribui para que o desdobramento das metas, ao longo dos diferentes níveis, possa ser mais bem compreendido por todos os empregados.

A existência de uma cultura organizacional cujos valores estimulem a geração de conhecimento e o livre fluxo de informações (SILVEIRA; BORENSTEIN; FOGLIATTO, 2001) - bem como a promoção de atitudes que conduzam ao melhoramento contínuo, ao aprendizado individual e organizacional, ao desenvolvimento de novas capacidades e à difusão das melhores práticas (KOTHA, 1996), além da inovação tecnológica (PINE, 1994) - representa importantes fatores para o sucesso da estratégia.

A existência de uma cultura organizacional cujos valores estimulem a geração de conhecimento e o livre fluxo de informações (SILVEIRA; BORENSTEIN; FOGLIATTO, 2001) - bem como a promoção de atitudes que conduzam ao melhoramento contínuo, ao aprendizado individual e organizacional, ao desenvolvimento de novas capacidades e à difusão das melhores práticas (KOTHA, 1996) -, além da inovação tecnológica (PINE, 1994), representam importantes fatores para o sucesso da estratégia.

Quando analisadas as diferenças entre a qualificação exigida dos profissionais que trabalham numa empresa que customiza produtos em massa e a exigida dos que trabalham numa empresa que fabrica em massa, constata-se que, no primeiro caso, os profissionais devem ser mais abertos a mudanças e aptos a absorver rapidamente a cultura da organização. Eles devem ser mais flexíveis. Para contribuir para o aumento da flexibilidade e conseguir agregar características culturais diferenciadas, a empresa envia pessoal para fábricas no exterior por um tempo determinado.

$\mathrm{Na}$ área de engenharia, por exemplo, há a necessidade de que pessoal tenha um conhecimento maior do mercado e sobre as aplicações do produto dos clientes, a fim de interagirem e opinarem. Conforme se depreende do pensamento do gerente de engenharia de motores industriais, isso possibilita oferecer diferentes alternativas de produtos para os clientes em seus diferentes segmentos.

Portanto, constata-se que o impacto do lançamento de um novo produto nos operadores que lidam exclusivamente com produção em massa é muito maior do que em uma empresa onde os processos e a cultura já contemplam essa possibilidade. Consequentemente, para as empresas tradicionais, o tempo para executar um produto diferenciado será maior. Nesse contexto, a importância apregoada pelas empresas quanto ao treinamento e ao desenvolvimento de sua mão-de-obra para o sucesso da estratégia de customização em massa também foi enfatizada por certos estudiosos em suas respectivas pesquisas, incluindo Lau (1995), Lee e Chen (2000) e Kotha (1996).

\section{Considerações finais}

Três fatores concorreram para que a empresa aqui analisada, inicialmente, um fabricante de produtos padronizados, desenvolvesse customização em massa: diferenciação, crescente demanda por produtos 
customizados e redução dos custos de fabricação. Nesse sentido, o processo de customização de motores pode se dar em diferentes estágios da cadeia de valor, sobressaindo-se o estágio de fabricação e o de montagem.

Por meio do levantamento de dados, foi possível identificar a utilização de um conjunto de práticas associadas a seis habilitadores: manufatura baseada no tempo, cadeia de suprimentos, flexibilidade do sistema produtivo, projeto do produto, aspectos organizacionais e tecnologia de informação.

Em relação às práticas adotadas pela manufatura baseada no tempo, destacam-se: CCQs, utilização tanto do layout celular quanto funcional, participação dos empregados e a utilização de estoques de componentes acabados. Em termos do projeto do produto, a adoção de componentes modulares na configuração dos modelos se mostra fundamental para reduzir tempo e custos. Isso, somado ao alinhamento entre a estrutura do projeto e a do processo, contribui para o sucesso da estratégia.

A tecnologia de informação - caracterizada pelo uso de bancos de dados, sistemas de informação, softwares CAD e configuradores de produto - agiliza as decisões e a troca de informações entre a empresa e os seus clientes, bem como entre as diversas áreas funcionais envolvidas na customização. Para aumentar a flexibilidade do sistema produtivo, são empreendidas diversas ações, tais como: troca rápida de ferramentas, balanceamento de linha, investimento em automação e geração de rotas alternativas.

A proximidade física com os fornecedores, a parceria firmada com os mesmos e o envolvimento destes, desde a fase do projeto de novos produtos, também se mostraram essenciais para se lidar com os problemas operacionais decorrentes da implementação do novo paradigma. Por fim, a manutenção de uma cultura devotada à simplicidade, a existência de um desenho organizacional enxuto, o estímulo à inovação e o constante aperfeiçoamento da mão-de-obra são fatores que se destacam em nível de gestão organizacional.

Assim, apesar da aparente incompatibilidade entre produção em massa e customização em massa, a adoção de uma estratégia em que ambas coexistam é viável numa empresa que atue em diferentes segmentos de mercado de um mesmo setor.

Nesse sentido, os principais benefícios observados dizem respeito ao intercâmbio de informações, ao conhecimento e à experiência entre as linhas de produtos. Ademais, a análise da demanda por produtos customizados tem servido para subsidiar a decisão de incluí-los nas linhas de produtos padronizados. 


\section{Referências}

ADDIS, M.; HOLBROOK M. B. On the conceptual link between mass customization and experiential consumption: an explosion of subjectivity. Journal of Consumer Behaviour, v.1, n.1, p.50-67, 2001.

AHLSTROM, P.; WESTBROOK, R. Implications of mass customization for operations management: an exploratory survey. International Journal of Operations and Production Management, v.19, n.3, p.262-274, 1999.

ALFORD, D.; SACKETT, P.; NELDER, G. Mass customisation: an automotive perspective. International Journal of Production Economics, v.65, p.99-110, 2000.

AMARO, G.; HENDRY, L.; KINGSMAN, B. Competitive advantage, customization and a new taxonomy for non make-to-stock companies. International Journal of Operations and Production Management, v.19, n.4, p.349-371, 1999.

BACIC, M. J. Rigidez e flexibilidade produtiva como frutos do processo competitivo. In: ENCONTRO NACIONAL DE ENGENHARIA DE PRODUÇÃO, 16., 1996, Piracicaba. Anais... Piracicaba: Unimep, 1996. 1 CD-ROM.

BERMAN, B. Should your firm adopt a mass customization strategy? Business Horizons, p.51-6o, July/Aug. 2002.

BROEKHUIZEN, T. L. J.; ALSEM, K. J. Success factors for mass customization: a conceptual model. Journal of Market-Focused M

BYRD, Terry Anthony. Information technology: core competencies and sustained competitive advantage. Information Resources Management Journal, Hershey, v.14, issue.2, p. 27-37, Apr./June 2001.

CARMO, F. D. C. F.; GAVRONSKI, I. Jit approach to mass customization: a case study. In: ENCONTRO DA ASSOCIAÇÃO DOS PROGRAMAS DE PÓS-GRADUAÇÃO EM ADMINISTRAÇÃO, 26., 2002, Salvador. Anais... Bahia: Anpad, 2002. 1 CD-ROM.

COLLIS, J. HUSSEY, R. Pesquisa em administração: um guia prático para alunos de graduação e pós-graduação. 2.ed. Porto Alegre: Bookman, 2005.

DAVIS, M. M.; AQUILANO, N. J., CHASE, R. B. Fundamentos da administração da produção. 3.ed. Porto Alegre: Bookman, 2001. DORNIER, P. et al. Logística e operações globais: texto e casos. São Paulo: Atlas, 2000.

DURAY, R. et al. Approaches to mass customization: configurations and empirical validation. Journal of Operations Management, v.18, p.605-625, Nov. 2000.

EISENHARDT, K. M. Building theories from case study research. The Academy of Management Review, v.14, n.4, p.532-550, Oct.1989.

FEITZINGER, E.; LEE, H. Mass customization at Hewlett-Packard: the power of postponement. Harvard Business Review, p.116-121, Jan./Feb. 1997.

GAITHER, N.; FRAZIER, G. Administração da produção e operações. 8.ed. São Paulo: Pioneira Thomson Learning, 2001.

GOLDHAR, J. D.; JELINEK, M. Plan for economies of scope. Harvard Business Review, v.61, n.6, p.141-148, Nov./Dec. 1983.

HART, C. W. L. Mass customization: conceptual underpinnings, opportunities and limits. International Journal of Service Industry Management, Bradford, v.6, issue 2, p.36-45, 1995.

JIAO, J.; MA, Q.; TSENG, M. M.. Towards high value-added products and services: mass customization and beyond. Technovation, V.23, n.10, p.809-821, Oct. 2003.

KOTHA, S. Mass customization: implementing the emerging paradigm for competitive advantage. Strategic Management Journal, v.16, p.21-42, Summer 1995 .

From mass production to mass customization: the case of the National Industry Bicycle Company of Japan. European Management Journal, v.14, n.5, p.442-450, 1996.

KOTLER, Philip. From mass marketing to mass customization. Planning Review, v.17, n.5, p.10-13, Sept./Oct. 1989.

KRIZNER, Ken. Individuality extends into manufacturing. Frontline Solutions, Duluth, v. 2, p.1-4, mar. 2001. 
LAU, Ronald S. M. Mass customization: the next industrial revolution. Industrial Management, v.37, n.5, p.18-19, Sept./Oct. 1995.

LEE, S.; CHEN, J. C. Mass customization: methodology for an apparel industry with a future. Journal of Industrial Technology, v.16, n.1, Nov./Jan. 2000.

MacCARTHY, B.; BRABAZON, P. G. In the business of mass customisation. IEE Manufacturing Engineer, p.30-33, Aug./Sept. 2003. BRAMHAM, J. Fundamental modes of operation for mass customization. International Journal of Production

Economics, v.85, n.3, p.289-304, Sep. 2003.

MERRIAM, S. B. Qualitative research and case study applications in education. San Francisco: Jossey-Bass, 1998.

PEPPERS, Don; ROGERS, Martha. Empresa 1:1: instrumentos para competir na era da interatividade. Rio de Janeiro: Campus, 1997.

PINE, B. J. Personalizando produtos e serviços - customização maciça. São Paulo: Makron Books, 1994.

; VICTOR, B.; BOYTON, A. C. Making mass customization work. Harvard Business Review, p.108-116, Sept./Oct. 1993.

ROSS, A. Selling uniqueness. IEE Manufacturing Engineer, p.260-263, Dec. 1996.

RUDDY, Mary. Mass customization now closer than ever. Machine Design, Cleveland, v.74, issue 12, p.59-61, June 2002.

SHEWCHUK, J. P., MOODIE, C. L. Flexibility and manufacturing system design: an experimental investigation. International Journal of Production Research, v.38, n.8, p.1801-1822, 2000.

SILVEIRA, G.; BORENSTEIN, D.; FOGLIATTO, F. S. Mass customization: literature review and research direction. International Journal of Production Economics, v.72, n.1, p.1-13, 2001.

TUBINO, Dalvio Ferrari. Sistemas de produção: a produtividade no chão de fábrica. Porto Alegre: Bookman, 1999.

YIN, Robert K. Estudos de caso: planejamento e métodos. 2. ed. Porto Alegre: Bookman, 2001.

ZINN, W. O retardamento da montagem final de produtos como estratégia de marketing e distribuição. Revista de Administração de Empresas, v.30, n.4, p.53-59, out./dez. 1990.

ZIPKIN, P. The limits of mass customization. Sloan Management Review, Cambridge, v.42, issue 3, p.81-87, 2001. 